\title{
Information through television: does it promote child safety?
}

\author{
Claes Sundelin, Finn Rasmussen, Ragnar Berfenstam, Kerstin Troedsson
}

\begin{abstract}
Objectives-First, to evaluate whether a local campaign to prevent childhood injuries increased parents' inclination to follow eight television programmes broadcast nationwide, and second, to assess whether parents reached by a local campaign benefitted more from the television programmes than those not reached by the campaign.
\end{abstract}

Methods-Before the television programmes were broadcast, all families with preschool children living in a typical Swedish municipality (the intervention area) received a letter from the head of the child health services encouraging them to watch the programmes. The local campaign also included face-to-face information and advice on childhood injuries at all day care centres and child health centres in the intervention area. After all the programmes had been broadcast, telephone interviews were conducted with one parent from $77 \%$ of all 1699 households with at least one preschool child in the intervention area, and with $87 \%$ of a random sample of 144 parents from other, similar municipalities.

Results and conclusions-The local campaign increased parents' inclination to follow the programmes. No significant association was found, however, between the number of programmes followed and measures undertaken in the homes as a direct consequence of the programmes. Nor was a significant association found between the number of programmes viewed and parents' attitudes towards risks. A local campaign may increase parents' awareness of information provided by the mass media on childhood injuries.

(Injury Prevention 1996; 2: 36-40)

Keywords: television, parent education, safety promo-

Uppsala University, Sweden, Department of Paediatrics

C Sundelin

F Rasmussen

$\mathrm{K}$ Troedsson

Department of Social Medicine

$R$ Berfenstam

Correspondence to: Dr Finn Rasmussen, Department of Paediatrics, University Children's

Hospital, S-751 85 Uppsala

Sweden.

In most industrialised countries injuries are responsible for a major proportion of mortality and morbidity in children. ${ }^{1-3}$ The mortality rate due to accidents among Swedish children $0-14$ years of age has gradually diminished from $25 / 100000$ children in a year in the mid-1950s to 5/100 000 in recent years. ${ }^{45}$ However, morbidity has probably not been reduced to the same extent, and recent reports indicate that $10-15 \%$ of all children $0-14$ years of age need primary or hospital care every year due to injuries. ${ }^{26}$

Health education on environmental hazards, and counselling and guidance to parents on how to avoid injuries, have been an important part of Sweden's child health care programme for more than three decades. In Sweden, district nurses running the child health centres have played a major part in this work. They visit nearly all parents with young children at home and offer advice on how to prevent injuries.

Mass media campaigns also have been used in many fields to promote health, for example by changing behaviours and life styles. ${ }^{7-11}$ The theoretical framework for such campaigns has been developed in mass communication research, sociology, and other disciplines. ${ }^{12-15}$ Research has shown that for mass media campaigns to be effective they must first reach their target group; then, contribute to increased knowledge and changing attitudes; and finally, effect behaviour change. Because very large target groups can be reached these campaigns need only a small success rate to produce higher numerical success than can be achieved by more effective health education programmes designed for small target groups. But there are some disadvantages in using television as a means of mass communication: the cost of transmission time is high; the message can rarely be tailored to the specific needs of the target group; and the direction of communication is one way.

In 1981 the British Broadcasting Company (BBC) decided to broadcast a series of programmes on child safety. Its preventive campaign was linked to a locally designed health education initiative. Colver et al conducted a study evaluating viewing and subsequent steps undertaken by families in the intervention area. ${ }^{16}$ Only $9 \%$ of those who received information from the programmes took any action to promote child safety in their homes. However, among parents in a comparison group who received home visits during which specific advice was given on how to improve child safety, $60 \%$ took action to make their homes safer.

In 1992 Sweden's National Television Com-

pany produced and broadcast a series of eight 10 minute programmes on child safety. The series, described in depth under Methods, was broadcast in October and November 1992 immediately before the evening's main newscast

In Enko̊ping, a municipality in Uppsala county, the broadcasts were preceded by a local information campaign aimed at encouraging all 
families with preschool children to follow the series, and to consider hazards in their homes.

The aim of this study were: (a) to investigate the extent to which Swedish families with preschool children followed the television programmes, (b) to analyse the extent to which the local campaign increased the parent's inclination to watch the programmes, and (c) to analyse if the programmes and the local campaign had an impact on the attitudes and behaviour of the audience with regard to the prevention of childhood injuries.

\section{Subjects}

\section{SETTINGS}

The municipality of Enköping has 36000 inhabitants and is located $60 \mathrm{~km}$ (38 miles) north west of Stockholm, Sweden's capital. In Enköping municipality there are about 3000 children 0-6 years of age. According to Statistics Sweden, Enköping is a typical municipality, that is an area with a population density in the middle range and with fewer than 45000 inhabitants.

\section{STUDY POPULATIONS}

Two groups of heads of household were selected from a population register covering the total population of Sweden. The study unit is a head of a household with at least one child born between 1 August 1986 and 1 February 1992. When the data were collected, at least one child in the selected households (families) was 6 months to 6 years of age.

\section{The intervention group}

All 1699 heads of household from the municipality of Enköping with at least one child born within the time period defined.

The non-intervention group

All heads of households with at least one child born within the period defined above, and who lived in one of the 97 typical municipalities located outside Uppsala county were eligible. From this large population of household heads, 144 were randomly sampled. Comparisons between the intervention and the nonintervention groups were planned only with respect to the proportions of parents who had watched the programmes. Therefore, a comparatively small sample of household heads was required from the non-intervention areas.

\section{Methods}

\section{THE TELEVISION PROGRAMMES}

All eight programmes started with a presentation of an actual accident. The course of events was illustrated in a realistic reconstruction. After that the affected family (parents and, if possible, the child) were interviewed about their experience and its consequences. Appropriate, specific recommendations concluded each programme.

The series covered bicycle injuries, pedest- rians, poisoning, drowning, burns, scalding, suffocation, and falls in this order.

\section{THE LOCAL INFORMATION CAMPAIGN}

All families in the intervention area with a child aged 6 months to 6 years received a personal letter from the head of child health services in Uppsala county, recommending that they follow the television programmes. The letter included information on the titles, dates, and times of the eight programmes to be broadcast.

In Sweden preschool teachers at day care centres and district nurses at child health centres have extensive contact with families with children of preschool age. The staff of all day care, child health, and primary health centres in the intervention area were involved in the campaign. They were instructed at special meetings and encouaged to inform all parents they met in their daily work of the programmes, and to give advice to parents on injury prevention.

A special brochure with information on the content of the programmes and transmission times was given to all parents visiting these institutions. Placards on childhood injuries and the television programmes were posted.

\section{THE INTERVIEWS}

The data were collected by professional interviewers employed by a private company specialising in household surveys. The interviews were conducted by telephone about one month after the last television programme. The parent who answered the telephone was asked questions about the number of programmes watched and family composition. For two parent families the respondent was also asked how many programmes the other parent had watched. The interview then continued with the parent who had watched the largest number of programmes. The interview included questions on which of the eight programmes the mother and/or father had seen, and questions on information received about the programmes from other sources, including newspapers, the child health or day care centre, neighbours, friends, etc. Questions were asked about safety equipment in the home before the television shows and preventive actions undertaken after seeing the programmes. Questions were also asked about the parents' age, working hours, occupation, and education.

Finally, parents were asked seven questions on attitudes to risk of childhood accidents (see Appendix). A scale, called 'proneness to protect' was constructed as the sum of the answers to these seven questions (range 1-7). A high score on this scale implies a greater inclination to protect a child against being injured. Records with a missing value were not included in the score. This scale was constructed ad hoc and has not been tested for validity or reliability.

\section{STATISTICAL ANALYSIS}

Because the number of programmes viewed by respondents did not follow a normal distribu- 
tion, the $\chi^{2}$ and Kolmogorov-Smirnov two sample tests were used. ${ }^{17}$

A multiple linear regression analysis was performed, with the logarithm of the number of programmes watched as the outcome variable. The following independent variables were initially entered into the regression analyses: number of preschool children in the family, one child under 2 years of age (yes or no), amount of information received (number of information sources recalled), recall of the letter from the head of child health services (yes or no), attitude to the time of transmission (positive or negative), active decision to watch the programmes (yes or no), immigrant family (yes or no), unemployed parent (yes or no), and parent with an upper secondary school or higher education (yes or no). The SAS software package was used for all statistical analyses. ${ }^{18}$

\section{Results}

Of all 1843 heads of household selected for the study from the intervention and the nonintervention areas, $1426(77 \%)$ agreed to be interviewed by telephone; $417(23 \%)$ were not interviewed for various reasons $(23 \%$ were non-respondents in the intervention area and $13 \%$ in the non-intervention areas). A correct telephone number could not be found for 46 (3\%). Of the 1426 respondents, $44 \%$ were men, $56 \%$ women; $92 \%$ were married or cohabiting; and $8 \%$ were single parents.

More programmes were watched in two parent families in the intervention and nonintervention areas. In the intervention areas $59 \%$ of either parent had seen at least one programme whereas in the non-intervention areas the corresponding figure was only $43 \%$. Eighteen per cent in the intervention area watched four or more broadcasts compared with $9 \%$ in the comparison area. Generally more mothers than fathers followed the broadcast.

For two parent families in the intervention area the mean number of programmes watched was 1.5 for mothers, 1.0 for fathers, and 1.7 for fathers or mothers. In the non-intervention areas the corresponding figures were $0.8,0.5$, and 0.9 . The Kolmogorov-Smirnov test clearly showed that significantly more programmes had been watched in the intervention area than in the non-intervention area.

In both areas taken together, at least one programme had been watched by $50 \%$ of mothers who were married or cohabiting compared with $37 \%$ of single mothers.

Table 1 shows that six of the eight programmes had been watched significantly more often

Table 1 Percentage in the intervention and non-intervention areas viewing the various television programmes

\begin{tabular}{lllll}
\hline Content & Order & $\begin{array}{l}\text { Intervention } \\
(n=1074)\end{array}$ & $\begin{array}{c}\text { Non-intervention } \\
(n=100)\end{array}$ & $p$ Value \\
\hline Bicyclist & 1 & 28 & 11 & $0 \cdot 000$ \\
Pedestrian & 2 & 14 & 6 & $0 \cdot 03$ \\
Poisoning & 3 & 23 & 14 & $0 \cdot 04$ \\
Drowning & 4 & 19 & 9 & 0.015 \\
Burns & 5 & 33 & 20 & $0 \cdot 007$ \\
Scalding & 6 & 19 & 7 & $0 \cdot 004$ \\
Suffocation & 7 & 18 & 11 & $0 \cdot 10$ \\
Falls & 8 & 17 & 12 & $0 \cdot 20$ \\
\hline
\end{tabular}

in the intervention area than in the nonintervention areas. The programmes were shown in the order listed in table 1 . In both, the programmes on burns and bicycle accidents were watched more often than those concerning scalds and pedestrian injuries. The differences between the proportion of watchers in the two areas was greater for fathers.

In families with at least one child under 2 years but no child older than 6 years, the proportions of parents who had watched specific programmes were: burns $(37 \%)$, poisoning $(28 \%)$, suffocation $(24 \%)$, and falls $(21 \%)$. Among families with at least one child 6 years of age or older but no child younger than 2 , the corresponding figures were all somewhat lower; $\chi^{2}$ tests for these four comparisons showed that all the proportions differed significantly $(p<0.01)$.

RECALL OF INFORMATION

In the intervention area $85 \%$ of the 752 families who had watched at least one programme recalled receiving some information before watching. In the non-intervention areas only $12 \%$ of families recalled some information on the series - for example from newspapers or trailers on television - before viewing a programme.

Of the 640 families in the intervention area who recalled receiving prior information, $60 \%$ remembered the letter they had received from the head of child health servies whereas information from child health, day care, and primary health care centres and other sources was only reported by $2-5 \%$ of the intervention area watchers.

Table 2 shows a multiple linear regression analysis including all factors significantly associated with the number of programmes watched. The information used in this analysis was only collected for families where a parent had watched at least one programme. Therefore the analysis in table 2 included only 718 two parent families belonging to this subgroup. The results shows that recall of the letter from the head of child health services before the broadcasts, recall of any other type of information about the programmes, active decision to watch made before broadcasting, convenient transmission time, and unemployment were positively and significantly associated with the number of programmes watched. Other independent variables (described in the Methods section), such as parents' educational level, were not included in the final model since they were not significantly associated with the number of programmes watched.

\section{SAFETY MEASURES IN THE HOME}

A high percentage of homes in both areas had taken safety measures before the broadcasts: $83 \%$ had childproof sockets, $63 \%$ stoves attached to the wall, $79 \%$ oven door protection, $49 \%$ hotplate protection, $78 \%$ lockable cupboards for medicines, $57 \%$ safety catches on windows, and $91 \%$ cycle helmets. 
Table 2 Multiple linear regression analysis with the logarithm of the number of programmes watched as outcome variable $(n=718)$

\begin{tabular}{|c|c|c|c|c|}
\hline $\begin{array}{l}\text { Dependent } \\
\text { variable }\end{array}$ & $\begin{array}{l}\text { No of } \\
\text { children }\end{array}$ & $\begin{array}{l}\text { Beta } \\
\text { estimate }\end{array}$ & $\begin{array}{l}95 \% \text { Confidence } \\
\text { interval }\end{array}$ & p Value \\
\hline & 0.73 & $(0.68$ to 0.79$)$ & 0.0001 \\
\hline & \multicolumn{4}{|c|}{ Recall of information letter } \\
\hline $\begin{array}{l}\text { Yes } \\
\mathrm{No}^{\star}\end{array}$ & $\begin{array}{l}379 \\
339\end{array}$ & 0.09 & $(0.03$ to 0.14$)$ & 0.0044 \\
\hline \multicolumn{5}{|l|}{ Other information source } \\
\hline $\begin{array}{l}\text { Yes } \\
\text { No }^{\star}\end{array}$ & $\begin{array}{l}220 \\
498\end{array}$ & $0 \cdot 12$ & $(0.07$ to 0.17$)$ & 0.0001 \\
\hline \multicolumn{5}{|c|}{ Decision to watch made in advance } \\
\hline $\begin{array}{l}\text { Yes } \\
\mathrm{No}^{\star}\end{array}$ & $\begin{array}{l}382 \\
336\end{array}$ & $0 \cdot 46$ & $(0.40$ to 0.52$)$ & 0.0001 \\
\hline \multicolumn{5}{|c|}{ Time of broadcasting appropriate } \\
\hline $\begin{array}{l}\text { Yes } \\
\text { No }\end{array}$ & $\begin{array}{l}352 \\
366\end{array}$ & $0 \cdot 27$ & $(0.21$ to 0.32$)$ & 0.0001 \\
\hline \multicolumn{5}{|l|}{ Position on labour market } \\
\hline $\begin{array}{l}\text { Unemployed } \\
\text { Employed* }\end{array}$ & $\begin{array}{r}40 \\
678\end{array}$ & $0 \cdot 13$ & $(0.02$ to 0.25$)$ & 0.024 \\
\hline
\end{tabular}

$\star^{\star}$ Reference group

Table 3 Multiple linear regression analysis with proneness to protect child against risks $(n=1126)$

\begin{tabular}{|c|c|c|c|c|}
\hline $\begin{array}{l}\text { Dependent } \\
\text { variable }\end{array}$ & $\begin{array}{l}\text { No of } \\
\text { children }\end{array}$ & $\begin{array}{l}\text { Beta } \\
\text { estimate }\end{array}$ & $\begin{array}{l}95 \% \text { Confidence } \\
\text { interval }\end{array}$ & p Value \\
\hline Intercept & & $30 \cdot 7$ & $(30.0$ to 31.5$)$ & 0.0001 \\
\hline $\begin{array}{l}\text { Logarithm of the No of } \\
\text { programmes watched }\end{array}$ & 1126 & 0.31 & $(0.02$ to 0.60$)$ & 0.0349 \\
\hline \multicolumn{5}{|l|}{ No of children } \\
\hline One ${ }^{\star}$ & 501 & & & \\
\hline Two or more & 625 & -0.59 & $(-1.00$ to -0.19$)$ & 0.0040 \\
\hline \multicolumn{5}{|l|}{ Family type } \\
\hline $\begin{array}{l}\text { Single mother } \\
\text { Two parents }\end{array}$ & 97 & 0.96 & $(0.25$ to 1.68$)$ & 0.0086 \\
\hline \multicolumn{5}{|l|}{ Language spoken } \\
\hline Scandinavian $\star$ & 1077 & & & \\
\hline Other & 49 & $2 \cdot 28$ & $(1.30$ to 3.28$)$ & 0.0001 \\
\hline \multicolumn{5}{|l|}{ Type of area } \\
\hline Intervention & 1035 & & & \\
\hline Non-intervention ${ }^{\star}$ & 91 & 0.48 & $(0.26$ to 1.21$)$ & 0.2025 \\
\hline
\end{tabular}

$\star$ Reference group. characteristics. No difference was found between intervention and non-intervention respondents. Only $4 \%$ of the variation in $R^{2}$ was explained by the regression model shown in table 3.

\section{ATTITUDES TO CAUSES OF INJURIES}

An attempt was also made to assess parents' beliefs concerning the causes of childhood injuries. All 1426 respondents were asked which of four factors they regarded as the most important 'cause' of preschool injuries. The responses were: 'children's curiosity and/or lack of maturity' ( $46 \%$ ), 'inappropriate supervision' $(23 \%)$, 'fate or bad luck' (14\%), 'the environment' $(12 \%)$, and 'do not know' (5\%). No differences were found in the distribution of responses between the two areas.

\section{Discussion}

The intervention area was a typical Swedish municipality. All heads of families with one child aged 6 months to 6 years comprised the study group. Non-response rates were low in both the intervention and non-intervention area. Even if the results cannot be generalised to the whole country, it is reasonable to believe that the findings apply to all similar municipalities in Sweden. Each programme was watched by about $2 \%$ (about 164000 ) of the Swedish population.

In both areas the proportion of viewers among families with preschool children ranged from $14 \%$ to $33 \%$, and $6 \%$ to $20 \%$, respectively for the different programmes. These findings are in accordance with other studies showing that the proportion of viewers in more motivated target groups may be much higher than in the whole population. ${ }^{71016}$ The transmission time, just before the main evening news, probably contributed to the rather high proportion of viewers.

The profile of viewers of the different programmes was similar in both areas. There were comparatively high proportions of viewers for the programmes on bicycle accidents and burnings, and lower proportions for suffocation and scalding. These differences may partly be explained by the relationship between age of children and programme content. Suffocation, which attracted a low proportion of viewers, was seen primarily by families with a child less than 2 years. The programme on bicycle accidents, on the other hand, attracted most viewers among families with older children - a majority in this study.

The local campaign apparently motivated parents to watch the series; significantly more programmes were watched in the intervention area than in the non-intervention areas. In the study of Colver et al $55 \%$ of the families did not watch any of the 'Play it Safe' programmes, ${ }^{16}$ whereas in our study the corresponding figures were $41 \%$ in the intervention area and $57 \%$ in the non-intervention areas.

The effects of mass media programmes on attitudes and behaviour are generally difficult to evaluate. ${ }^{12-15}$ The present study shows that
PRONENESS TO PROTECT CHILD AGAINST
INJURIES
Table 3 shows a multiple linear regression
analysis including all 1126 respondents with
valid values on the variables included. The
results reveal a weak positive association
between the number of programmes watched
and parents' proneness to protect their child
(the outcome variable). Single parents, those
speaking a non-Scandinavian language, and
parents having only one child were more prone
to provide protection than those without these

PRONENESS TO PROTECT CHILD AGAINST
INJURIES
Table 3 shows a multiple linear regression
analysis including all 1126 respondents with
valid values on the variables included. The
results reveal a weak positive association
between the number of programmes watched
and parents' proneness to protect their child
(the outcome variable). Single parents, those
speaking a non-Scandinavian language, and
parents having only one child were more prone
to provide protection than those without these

PRONENESS TO PROTECT CHILD AGAINST
INJURIES
Table 3 shows a multiple linear regression
analysis including all 1126 respondents with
valid values on the variables included. The
results reveal a weak positive association
between the number of programmes watched
and parents' proneness to protect their child
(the outcome variable). Single parents, those
speaking a non-Scandinavian language, and
parents having only one child were more prone
to provide protection than those without these 
only one third of the families where both parents watched at least two programmes undertook any measure to improve child safety. One possible explanation was the prior widespread use of safety equipment in the home. Much of what could be done had apparently already been done. As a consequence, the most common measure reported was an increase in supervision.

In this study it was impossible to measure the effect of the television series on attitudes because no such information was available beforehand. The parents' proneness to protect their child against injuries correlated only weakly with the number of broadcasts watched. The explanatory power of a regression model (including number of programmes watched and certain sociodemographic variables) with parents' proneness to protect their child as the dependent variable was low.

This suggests that a majority of parents perceive childhood injuries as problems related to developmental issues or 'fate' rather than environmental problems - at least when basic preventive actions have already been undertaken. This fact should be considered when developing preventive programmes. This 'fatalistic' attitude, however, showed no relationship with the number of programmes watched.

\section{SUCCESS OR FAILURE?}

The mean number of programmes watched by parents was rather low, as was the frequency of preventive measures undertaken by the families as a consequence of seeing the programmes. However, a total of 1.3 million television programmes watched in a country with 8.8 million inhabitants may have long term important effects that are difficult to evaluate in this type of study. Moreover, it is impossible to assess all situations where information given by the media might decrease the risk for childhood injury. This work was supported by grants from the County Council of
Uppsala, the Skandia Insurance Group and the former Swedish Child Environmental Council.
1 Bergman AB, Rivara FP. Sweden's experience in reducing childhood injuries. Pediatrics 1991; 88: 67-74.

2 Swedish Environmental Counci! and Folksam Insurance Group. Child safety work in Sweden. Observance of a 35th anniversary, memories and experiences for the future. (Stockholm: Swedish Environmental Council and the Folksam Insurance Group, 1989.

3 Avery JG, Jackson RH. Children and their accidents. London: Edward Arnold, 1993.

4 Statistics Sweden. Causes of death 1950. Stockholm: Statistics Sweden, 1951.

5 Statistics Sweden. Causes of death 1992. Stockholm: Statistics Sweden, 1993.

6 Schelp L. Community intervention and changes in acciden patterns in a rural Swedish municipality. Health Promotion 1987; 2: 109-25.

7 Fonnebo V, Sögaard AJ. The penetrating educational effect of a mass-media based fund-raising campaign 'Heart for Life'. Scand 7 Soc Med 1990; 18: 185-93.

8 Herlitz J, Blohm M, Hartford M, et al. Follow up of a 1-year media campaign on delay times and ambulance use in suspected acute myocardial infarction. Eur Heart $\mathcal{f} 1992$; 13: $171-7$.

9 Jason LA, Greiner BJ, Naylor K, Johnson SP, Egeren LV. A large-scale, short-term, media-based weight-loss program. American fournal of Health Promotion 1991; 5: $432-7$

10 Shelley JM, Irwing LM, Simpson JM, Mascakill P. Evaluation of a mass-media-led campaign to increase PAP smear screening. Health Education Research 1991; 6: 267-77.

11 Frisby ML, Hill JH. A community's response to childhood drownings. A model for accident prevention. Critical Care Nursing Clinics of North America 1991; 3: 373-9.

12 McQuail D. Mass communication theory. London: Sage Publications, 1987.

13 Alcalay $\mathrm{R}$. The impact of mass communication campaigns in the health field. Soc Sci Med 1983; 17: 87-94.

14 Flay BR. Massmedia and smoking cessation: a critical review. Am $\mathcal{J}$ Public Health 1987; 77: 153-60.

15 Warner KE. Television and health education. Stay tuned. Am f Public Health 1987; 77: 140-2.

16 Colver AF, Hutchinson PJ, Judson EC. Promoting children's home safety. BMf 1982; 285: 1177-80

17 Siegel S, Castellan NJ. Nonparametric statistics for the behavioral sciences. New York: McGraw-Hill, 1988

18 SAS Institute. SAS/STAT guide for personal computers. Version 6 edition. Cary, NC: SAS Institute, 1987.

\section{Appendix}

'Proneness to protect' scale score

At what age do you believe that a child can be allowed to:

(1) Be alone outside the home if he/she can be monitored through a window?

(2) Be alone outside the home if he/she cannot be monitored through a window?

3) Cross the street alone in a sparsely trafficked area?

(4) Walk alone in the street?

5) Ride a bike alone in the street?

6) Be alone near a stream or lake?

7) Be alone in the home?

${ }^{\star}$ Score is the sum of all coded responses. 